\title{
Works In Progress: Impact of a Pilot Summer Innovation Internship on Stu- dent Attitudes towards Engineering Design and Entrepreneurship
}

\section{Dr. Jennifer H Choi, University of California, Davis}

Jennifer Choi is currently an Assistant Professor of Teaching in the Department of Biomedical Engineering (BME) at UC Davis. In addition to teaching core undergraduate courses, Jennifer is aimed at integrating engineering design principles and hands-on experiences throughout the curriculum, and playing an active role in the senior design course. She has interests in engineering education, curricular innovation, as well as impacting the community through increased K-12 STEM awareness and education. Prior to joining UC Davis, Jennifer taught in the BME Department at Rutgers University, and was a postdoctoral fellow at Advanced Technologies and Regenerative Medicine, LLC. She received her doctoral degree in Biomedical Engineering from Tufts University, M.S. degree from Syracuse University, and B.S. degree from Cornell University. 


\section{Works In Progress: Impact of a pilot summer innovation internship on student attitudes towards engineering design and entrepreneurship}

Introduction

The interdisciplinary nature of the senior design course requires students to possess a broad skill set. Prior to our program's senior design course, students receive some general training in engineering design during the first and second year required classes, though specialized skills often needed are not formally introduced or practiced. In response, efforts are being made to develop specific skills-building modules and opportunities for students to gain practical experience for application to their senior design project, but ultimately to improve the skillset of graduating students. These include the development of new hands-on curricular modules and a summer innovation internship, aimed to enhance students' technical skills, professional development skills, and entrepreneurship knowledge.

This study is focused on our inaugural Summer Innovation Internship, which provided an opportunity for selected students to be actively engaged in parts of the innovation process. Beginning with needs finding, students underwent clinical immersion through observations in various clinical departments at the institution's medical center and school of veterinary medicine for six weeks. Students also participated in a Biomedical and Engineering Entrepreneurship Academy (BMEA), in which they learned about how to determine the commercial potential of an idea. At the completion of the summer internship, students were expected to have a firm grasp of how to effectively engage with clinicians to identify relevant clinical needs and have a clear understanding of how ideas move forward in the context of critical networks of entrepreneurs and investors.

The purpose of this pilot study was to gain understanding of the perceived impact of our institution's Summer Innovation Internship on students' attitudes towards engineering design and entrepreneurship. Several studies have investigated students' attitudes towards entrepreneurship, or entrepreneurial mindset, through various curricular and co-curricular activities ${ }^{1-4}$. To build upon the growing body of literature that support the advantages of an entrepreneurial mindset, we are seeking to understand how engineering students' entrepreneurial attitudes affect their perceptions of the engineering design process and performance in the senior design course. This would provide additional insights regarding integration of entrepreneurship education and training in the undergraduate biomedical engineering curriculum.

Methods

Internship Selection and Program Structure

Applications were solicited from biomedical engineering undergraduate students. Applications consisted of a resume, transcript, and personal statement. Following in-person interviews, four lower division and four upper division students were selected to participate in the inaugural seven week summer innovation internship (Figure 1). 
The internship began with a two-day workshop focused on needs-finding, needs statement development, conducting observations, ethics in observations, value exploration and design thinking. Over the course of seven weeks, students were immersed in full-time clinical observations at both the medical center and school of veterinary medicine. Each intern underwent 3 weeks of clinical observations at each clinical site, with a minimum of seven days in any one clinical department. Participating clinical departments are indicated in Figure 1. Interns were required to document their clinical observations in a physical notebook and provide weekly summaries of observations in a shared Google drive document. Virtual group meetings were also held weekly for a discussion and debrief session. In addition to clinical observations, students participated in a Biomedical + Engineering Entrepreneurship Academy (BMEA) hosted by our institution's institute for innovation and entrepreneurship, housed in the School of Management. The BMEA serves as a catalyst for idea translation, and integrates various teaching modalities including lectures, group exercises, and individual projects to aid participants in identifying, designing and validating market opportunities for their research and ideas. At the conclusion of the seven week internship, each intern presented their observations along with supporting clinical and market research for one identified unmet need.

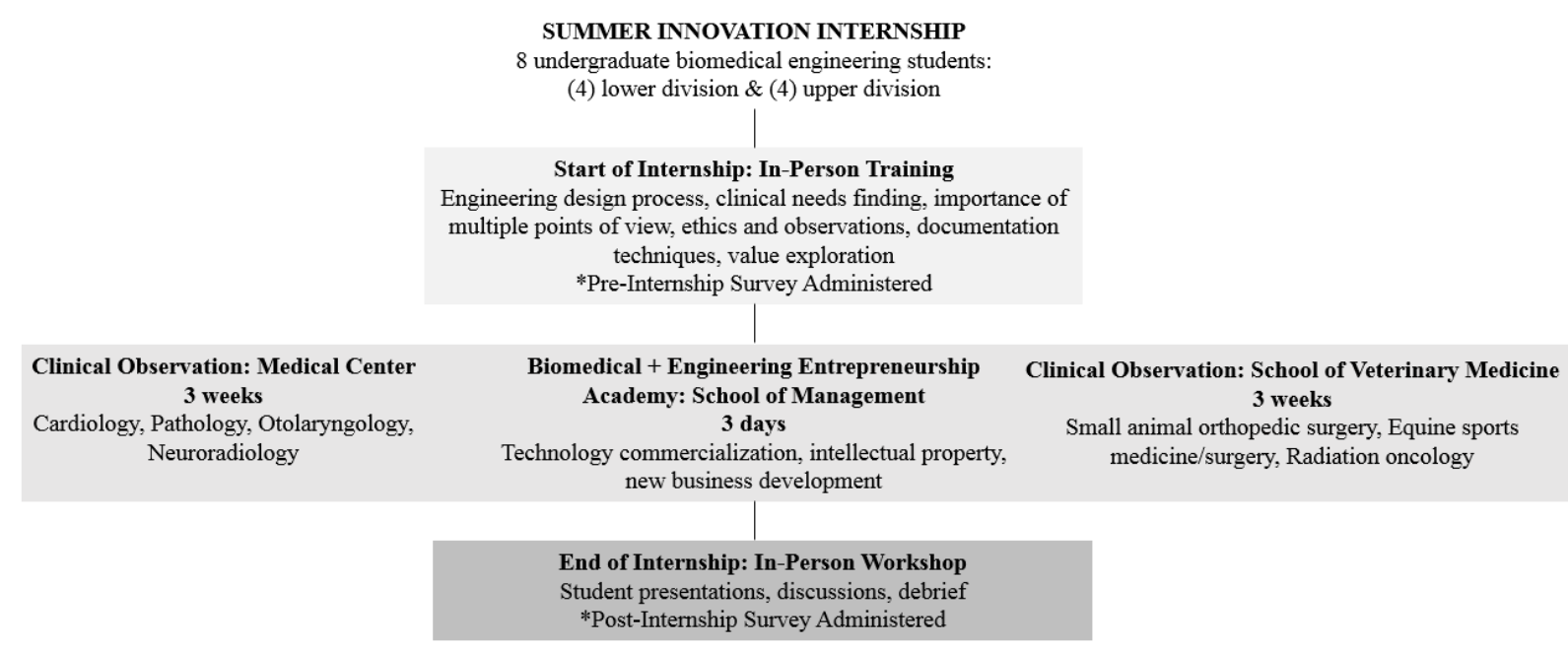

Figure 1. Summer Innovation Internship Program Overview. Participating clinical departments, in-person workshop topics, and survey administration timeline specified.

\section{Research Study}

This pilot study was designed to increase our understanding of how participating students perceived the impact of the internship program on their attitudes towards entrepreneurship/business and needs finding. A thirty eight question Likert survey, modified with permission from a recently published entrepreneurial mindset instrument ${ }^{5}$, was administered on the first and last day of the seven week internship. Survey questions were focused on student attitudes towards entrepreneurship, level of understanding and confidence in entrepreneurial/business concepts, and level of understanding and confidence in the needs finding process (Table 1). We hypothesized that participation in the internship will have a positive impact on attitudes in each thematic area. The study protocol (ID 1246604-1) was reviewed and determined exempt by the institution's Institutional Review Board. 
Pre-internship and post-internship Likert scale responses were converted to the following quantitative values: I don't understand (0), strongly disagree (1), disagree (2), neutral (3), agree (4), and strongly agree (5). Average scores for each theme identified in Table 1 and changes in self-reported scores from the pre-internship to post-internship survey were determined. A paired t-test was performed to determine statistical significance from pre to post internship $(\mathrm{p}<0.05)$.

\begin{tabular}{|l|l|}
\hline Theme & Question \\
\hline 1. Attitude towards & Q. My career goal is to become a professional with an entrepreneurial \\
& mindset. \\
Q. I'd like to take some entrepreneurship courses in college.
\end{tabular}

Table 1. Survey themes and corresponding questions using the following Likert scale: I don't understand, strongly disagree, disagree, neutral, agree, and strongly agree.

\section{Results}

Pre-internship survey responses (Figure 2) indicated that participants generally rated their understanding and confidence in the needs finding process higher than that of entrepreneurial/business concepts coming into the internship. Average Likert score for understanding the needs finding process was 3.75, while average score for understanding entrepreneurial/business concepts was a 2.84. Likewise, average score for confidence in the needs finding process was 3.63, while average score for confidence in entrepreneurial/business concepts was 2.54. Theme 1, attitude towards entrepreneurship, reported the highest average Likert score (3.81) by the participants at the start of the internship.

Post-internship survey responses (Figure 2) at the conclusion of the internship indicated an increase in participants' self-reported level of understanding and confidence in both entrepreneurial/business concepts and the needs finding process. All participants agreed or strongly agreed with statements regarding level of understanding and confidence in the needs finding process (average Likert score of 4.88 for both). Likewise, participants rated their understanding and confidence of entrepreneurship/business concepts at 4.02 and 3.65, 
respectively. Interestingly, reported attitudes towards entrepreneurship, measured by a career goals question and desire to take entrepreneurship classes, decreased from an average score of 3.81 in the pre-internship survey to 3.63 in the post-internship survey. Changes in self-reported Likert scores are summarized in Figure 3 below.

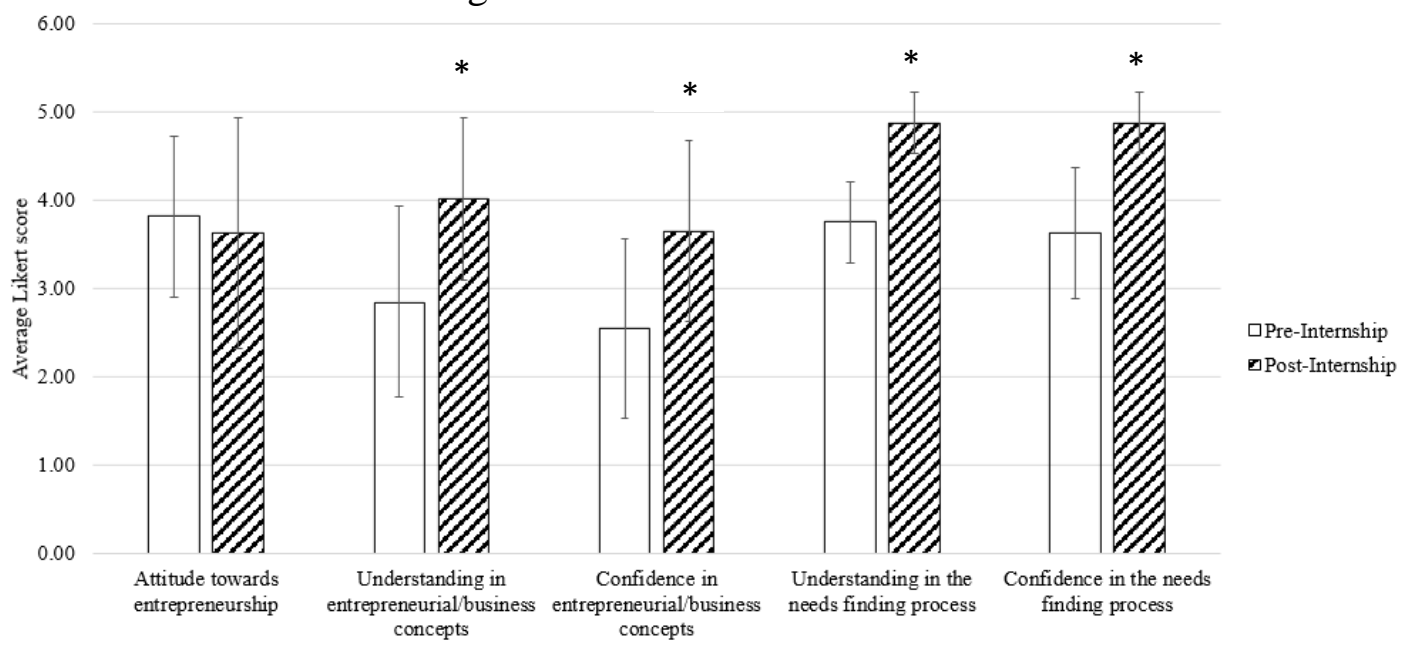

Figure 2. Average self-reported Likert score on pre-internship and post-internship survey. Error bars represent $+/$ - standard deviation. *Significant change from pre-internship score $(\mathrm{p}<0.05)$.

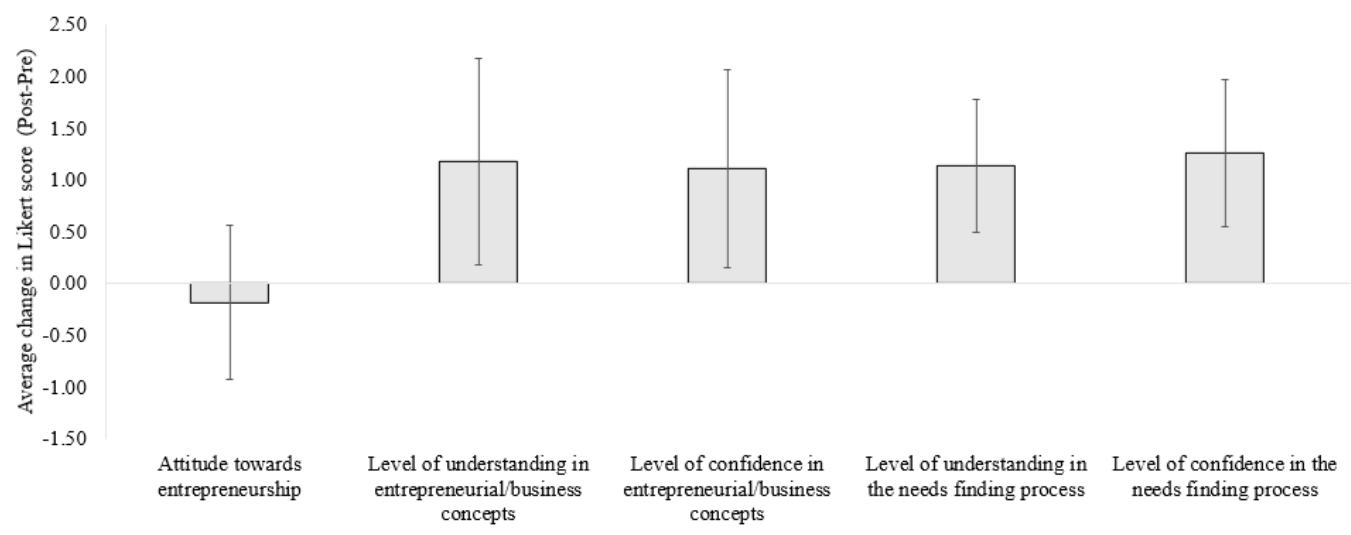

Figure 3. Average change (post-pre) in Likert scores across all participants for each theme. Error bars represent +/- standard deviation.

Implications and Conclusions

Students' perceived level of understanding and confidence in the needs finding process increased from the start to end of the summer internship. This may suggest that actively undergoing the needs-finding process helps to solidify understanding and increase confidence in this early stage of the engineering design process, as similarly reported by other programs ${ }^{6}$. Informal conversations with participants indicated that participation in the BMEA was the first time they were exposed to entrepreneurial/business concepts, which may be reflected in the reported increase in understanding and confidence in these areas at the conclusion of the internship. The reported decrease in attitudes towards entrepreneurship however, as reflected by students' level of agreement with becoming a professional with an entrepreneurial mindset and desire to take entrepreneurship classes, may be indicative of several factors. Students may have realized 
through the experience that they are not interested in entrepreneurship itself, but they may also not understand what being a professional with an entrepreneurial mindset actually means. Increased instruction may be needed both within the summer internship but also in the curriculum to more effectively inform students of entrepreneurial mindset and the value that it brings to any professional ${ }^{7}$.

As part of a multi-year study, this pilot study assessed students' self-perceptions on entrepreneurship/business and needs finding before and after the summer internship. Ongoing studies are assessing the impact of the summer internship and curricular skills-building modules on performance in the senior design course. Additional insights regarding students' perceptions on entrepreneurial/business concepts and needs-finding before and after the summer internship will be obtained through both interviews and focus groups. Future studies to investigate specific learning gains in these areas are certainly needed to provide evidence-based conclusions and recommendations.

Funding Support

Research reported in this publication was supported by the National Institute of Biomedical Imaging And Bioengineering of the National Institutes of Health under Award Number R25EB012963. The content is solely the responsibility of the authors and does not necessarily represent the official views of the National Institutes of Health.

\section{References}

${ }^{1}$ S. Purzer, N. Fila and K. Nataraja, "Evaluation of Current Assessment Methods in Engineering Entrepreneurship Education", Advances in Engineering Education, vol. 5, no. 1, 2016. ${ }^{2}$ B. Przestrzelski and J. DesJardins, "The DeFINE Program: A Clinical Immersion for Biomedical Needs Identification", in American Society for Engineering Education Conference Proceedings 2015, Seattle, 2015.

${ }^{3}$ B. Moyer, "Collaborative Efforts to Encourage Entrepreneurial Mindsets", in American Society for Engineering Education Conference Proceedings 2016, New Orleans, 2016.

${ }^{4}$ Borchers, A. and Park, S. H., "Undergraduate Engineering Student Attitudes Toward Entrepreneurship”, in American Society for Engineering Education Conference Proceedings 2009, Austin, 2009.

${ }^{5}$ C. Li, R. Harichandran, M. Carnasciali, N. Erdil and J. Nocito-Gobel, "Development of an Instrument to Measure the Entrepreneurial Mindset of Engineering Students", in American Society for Engineering Conference Proceedings 2016, New Orleans, 2016.

${ }^{6}$ Stirling S. and Kotche, M, "Clinical Immersion Program for Bioengineering and Medical Students”, in American Society for Engineering Education Conference Proceedings 2017, Columbus, 2017.

${ }^{7}$ Rae D. and Melton, D, "Developing an Entrepreneurial Mindset in US Engineering Education: An International View of the KEEN Project”, The Journal of Engineering Entrepreneurship, vol. 7, no. 3, 2016. 